\title{
Resposta Funcional de Scymnus (Pullus) argentinicus (Weise) (Coleoptera: Coccinellidae) a Diferentes Densidades do Pulgão Verde Schizaphis graminum (Rond. ) (Homoptera: Aphididae)
}

\author{
Gilvânia F. Vieira', Vanda H. P. Bueno ${ }^{1}$ e Alexander M. Auad ${ }^{1}$. \\ ${ }^{1}$ Universidade Federal de Lavras, Departamento de Entomologia, Caixa postal, 37 , \\ 37200.000, Lavras, MG.
}

An. Soc. Entomol. Brasil 26(3): 495-502 (1997)

Functional Response of Scymnus (Pullus) argentinicus (Weise)

(Coleoptera: Coccinellidae) at Differents Densities of Greenbug

Schizaphis graminum (Rond.) (Homoptera:Aphididae)

\begin{abstract}
The functional response, search time and handling time of the predator Scymnus (Pullus) argentinicus (Weise) were evaluated. Nymphs of 3rd and 4th instars of the greenbug, Schizaphis graminum (Rond.), were provided as food. The statistical design was randomly in a factorial $3 \times 5$, with three densities of the greenbug $(10,25,35$ nymphs $)$ and four instars and adult of the predator, in 10 replications. Tests were conducted in an environmental chamber at $25 \pm 1{ }^{\circ} \mathrm{C}, 70 \pm 10 \% \mathrm{RH}$ and 14 hours photophase. For both larvae and adults of $S$. (Pullus) argentinicus the amount of predated nymphs increased with the increment of aphid densities, until reaching a plateau (functional response Type II). Predation in the 4th instar was higher and greater for the density of 35 nymphs compared to the densities of 10 and 25 nymphs. The increment in predation increased, from density 10 to 25 , but decreased at density 25 to 35 nymphs. The search time incresead gradually with the age of the predator, while the handling time decreased with the age. Adult females presented higher predation and searched faster for prey than males. Searching time decreased with the increase in aphid density.
\end{abstract}

KEY WORDS: Insecta, predation, functional response.

RESUMO- Avaliou-se a resposta funcional, o tempo de busca e de manuseio da presa pelo predador Scymnus (Pullus) argentinicus(Weise). Como alimento foram oferecidas ninfas de $3^{\underline{0}}$ e $4^{0}$ ínstares do pulgão verde Schizaphis graminum (Rond.). O delineamento experimental foi o inteiramente casualizado, em esquema fatorial $3 \times 5$, em três densidades (10, 25 e 35) de ninfas do pulgão e quatro ínstares larvais e adulto do predador, em 10 repetições. Os insetos foram mantidos a $25 \pm 1{ }^{\circ} \mathrm{C}, 70 \pm 10 \%$ UR e fotofase de 14 horas. Tanto para larvas como para adultos de $S$. (Pullus) argentinicus, a quantidade de ninfas predadas aumentou com o incremento da densidade da presa, até atingir um platô (resposta funcional Tipo II ). A capacidade predatória no $4^{0}$ ínstar foi maior em relação a todos os outros ínstares e diferiu significativamente na densidade de 35 ninfas, quando comparada com as densidades de 10 e 25 , o mesmo ocorrendo para machos e fêmeas. O incremento da predação foi maior ao passar da densidade 10 para 25 , tornando-se menor ao passar de 25 para 35 . O tempo de busca aumentou gradualmente com a idade do predador, enquanto que o tempo de 
manuseio decresceu com a idade. Em um mesmo período, as fêmeas predaram mais que os machos e também buscaram a presa mais rapidamente.

PALAVRAS-CHAVE: Insecta, predação, resposta funcional.

Espécies do gênero Scymnus são citadas em vários trabalhos (Hagen \& Van Den Bosch 1968, Bartoszeck 1975, Gravena 1979, Gassen \& Tambasco 1993), como sendo predadoras de afideos. Trabalhos realizados no Brasil com coleópteros do mesmo gênero (Bartoszeck 1976, Arioli \& Link 1987), identificaram espécies de Scymnus para uso como agentes de controle biológico. Porém, as informações a respeito do comportamento desses predadores em relação às diferentes densidades de uma presa são inexistentes.

A resposta dos inimigos naturais a mudanças na densidade da presa influencia significativamente a relação predador-presa. Uma dessas constatações baseia-se na resposta funcional, que é o número de presas atacadas pelo predador em função da sua densidade (Solomon 1969). Esse autor observou que um aumento na disponibilidade de presas pode levar o predador a um aumento do consumo, até um determinado limite, uma vez que as oportunidades de encontro para ataque da presa serão maiores com o tempo.

De acordo com Tostowaryk (1972), os componentes da resposta funcional inclui a duração do tempo em que o predador e a presa ficam expostos um ao outro; a taxa de busca bem sucedida; e o tempo de manuseio. Holling (1959) propôs três tipos básicos de resposta funcional dos predadores: Tipo I, onde há um aumento linear, até um máximo, no número de presas ingeridas por predador, à medida que a densidade da presa aumenta; Tipo II, onde a resposta aumenta numa taxa decrescente em direção a um valor máximo; e Tipo III, onde a resposta é sigmóide e aproximando-se de uma assíntota superior. As respostas Tipo II são geralmente associadas com predadores invertebrados e as respostas Tipo III são consideradas mais características de predadores vertebrados, que podem aprender a "se concentrar"em uma presa que se torna abundante.

Neste trabalho, estudou-se a resposta funcional de ínstares larvais e do adulto de Scymnus (Pullus) argentinicus (Weise), em relação às densidades variáveis de ninfas de Schizaphis graminum (Rond.).

\section{Material e Métodos}

Criação de Manutenção. Os pulgões foram coletados em folhas de sorgo (Sorghum bicolor), no Centro Nacional de Pesquisa de Milho e Sorgo-CNPMS, Embrapa, Sete Lagoas, MG. Ninfas e adultos do pulgão foram colocados em secções de folhas de sorgo (cv. BR 301), sendo acondicionados em copos de plástico $(50 \mathrm{ml})$, contendo água até sua metade, permitindo a conservação da folha por maior tempo. Os copos foram vedados com discos de isopor de $4,0 \mathrm{~cm}$ de diâmetro. As folhas foram trocadas a cada dois dias, devido o rápido aumento populacional dos pulgões. A criação de manutenção de $S$. (Pullus) argentinicus foi conduzida em câmara climática $\left(25 \pm 1{ }^{\circ} \mathrm{C}\right.$, UR $70 \pm 10 \%$ e fotofase de 14 horas).

Criação de Manuseio. Utilizando-se pincéis, fêmeas adultas do pulgão foram retiradas da criação de manutenção e colocadas sobre secções de folhas de sorgo, nas mesmas condições da criação de manutenção. A cada 24 horas, um número variável de 10 a 12 fêmeas foram colocadas nas secções de folhas, para produção de ninfas e retiradas após 24 horas, permanecendo nas folhas somente as ninfas de $1^{0}$ ínstar. Dessa forma, obteve-se o número diário de ninfas de $3^{0}$ e $4^{0}$ ínstares necessário para a condução da parte experimental.

Larvas e adultos de S. argentinicus foram 
coletados no pomar de fruticultura (Citrus sp.) do Campus da Universidade Federal de Lavras. Os insetos foram mantidos em copos de plástico $(5,5 \mathrm{~cm} \times 8 \mathrm{~cm})$ com papel filtro na base, umedecido com água e vedados com PVC laminado $\mathrm{O}$ alimento fornecido foram ninfas e adultos de $S$. graminum. Os adultos recém emergidos foram separados em grupos de 10 casais e mantidos nos copos de plástico para obtenção de ovos. As larvas obtidas foram transferidas para outro recipiente para acompanhamento e separação dos estádios larvais, de acordo com o ínstar.

Montagem do Experimento. Da criação de manuseio de $S$. graminum, foram retiradas as ninfas de $3 \underline{0}$ e $4 \underline{0}$ ínstares, que foram separadas nas densidade de 10, 25 e 35 ninfas, num total de 150 recipientes (50 para cada densidade, considerando as 10 repetições). O estágio larval de $S$. argentinicus (10, $2^{0}, 3^{0}$ e $4^{0}$ ínstares) e o adulto constou de 10 indivíduos para cada densidade. As ninfas foram confinadas nos copos de plástico, contendo discos foliares de sorgo de 3,6 cm de diâmetro, sendo os copos cobertos com PVC laminado transparente, delimitando-se, assim, a área de ataque de $S$. argentinicus. As avaliações foram feitas a cada 24 horas, observando-se o número de ninfas remanescentes em relação à sua densidade inicial, determinando-se, então, o tipo de resposta funcional apresentada em cada ínstar e adulto de $S$. argentinicus. Essas avaliações foram realizadas durante 64 dias para o estágio adulto, periodo este que corresponde ao período vegetativo do sorgo BR 301 utilizado nas criações do pulgão.

Utilizando recipientes de criação de $S$. argentinicus, avaliou-se o tempo de busca e manuseio da presa pelo predador. Nos recipientes foram colocados as diferentes densidade do pulgão, sendo o predador ( $1^{\underline{0}}$, $2^{\underline{0}}, 3^{0}$ e $4^{0}$ ínstares larvais e adulto) liberado no centro do recipiente. Cronometrou-se o tempo em que o predador ficou exposto à presa até a sua captura (tempo de busca) e o período em que o predador ficou em contato com a presa, alimentando-se desta (tempo de manuseio). O tempo de busca do predador e tempo de manuseio das presas pelas larvas e adultos foram avaliados individualmente, dentro de cada densidade, nas 10 repetições.

Para avaliar a resposta funcional, utilizouse delineamento inteiramente casualizado, em esquema fatorial $5 \times 3$, com 10 repetições. Os tratamentos consistiram das combinações do $1^{\underline{0}}, 2^{\underline{0}}, 3^{0}$ e $4^{4^{0}}$ ínstares e do adulto de $S$. argentinicus nas densidades de 10,25 e 35 ninfas do pulgão $S$. graminum. As análises de variância foram realizadas para o delineamento considerado, transformando os dados por $(\mathrm{x}+1)^{2}$, para tempo de busca e $\sqrt{x}$ para tempo de manuseio pelas larvas e adultos do predador.

\section{Resultados e Discussão}

Verificou-se uma tendência de aumento da predação pelas larvas com o aumento da densidade da presa (Tabela 1), sendo maior ao passar da densidade 25 para 35 , podendo indicar, neste caso, que é em torno da densidade 35 que se encontra a disponibilidade de presas que coincide com as necessidades nutricionais da fase larval. O $1^{0}$ ínstar apresentou um menor consumo, com média de 3,$0 ; 4,6 ; 12,3$ ninfas, respectivamente para as densidades 10,25 e 35 , provavelmente devido a um menor requerimento nutricional, enquanto que o $2^{\underline{0}}$ ínstar apresentou um consumo maior, com médias de 6,$5 ; 12,3 ; 35,7$ ninfas, respectivamente, em relação ao $1^{\underline{0}}$ e $3^{0} \quad(3,8 ; 7,6 ; 32,7$ ninfas, respectivamente) ínstares, devido ao maior tempo de duração do $2^{\underline{0}}$ ínstar; o mesmo ocorrendo com o $4^{0}$ ínstar $(16,6 ; 47,2 ; 98,5$ ninfas) em relação aos demais (Tabela 1). Garcia et al.(1975) em estudos com Scymnus sp. concluiram que uma maior capacidade de predação em estágios mais avançados pode ser explicado por uma maior exigência nutricional e por maior mobilidade da larva ao aumentar de tamanho, o que resulta em uma maior área de busca pela mesma.

Foi observado que tanto para a fase larval como para o adulto, S. (Pullus) argentinicus apresentou um maior consumo de presas em função do aumento da densidade (Tabela 2). 


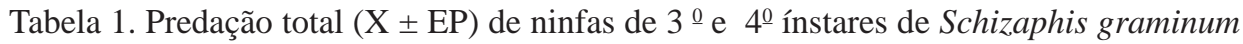
em diferentes densidades, por larvas de $1^{0}, 2^{0}, 3^{0}$ e $4^{0}$ ínstares de Scymnus (Pullus) argentinicus.

\begin{tabular}{|c|c|c|c|c|c|c|}
\hline \multirow{2}{*}{$\begin{array}{l}\text { Predador } \\
\text { (ínstar) }\end{array}$} & \multicolumn{5}{|c|}{ Densidade de afídeos ${ }^{1}$} & \\
\hline & 10 & & 25 & & 35 & \\
\hline $1^{0}$ & $\begin{array}{c}3,0 \pm 0,03 \mathrm{c} \\
(\mathrm{n}=10)\end{array}$ & A & $\begin{array}{c}4,6 \pm 0,09 d \\
(n=10)\end{array}$ & B & $\begin{array}{c}12,3 \pm 0,13 \mathrm{c} \\
(\mathrm{n}=10)\end{array}$ & $\mathrm{C}$ \\
\hline $2^{\underline{0}}$ & $\begin{array}{c}6,5 \pm 0,11 b c \\
(\mathrm{n}=10)\end{array}$ & A & $\begin{array}{c}12,3 \pm 0,17 b c \\
(\mathrm{n}=10)\end{array}$ & B & $\begin{array}{c}35,7 \pm 0,21 b \\
(\mathrm{n}=10)\end{array}$ & $\mathrm{C}$ \\
\hline $3^{\underline{0}}$ & $\begin{array}{c}3,8 \pm 0,10 \mathrm{c} \\
(\mathrm{n}=10)\end{array}$ & A & $\begin{array}{c}7,6 \pm 0,11 \mathrm{~cd} \\
(\mathrm{n}=10)\end{array}$ & B & $\begin{array}{c}32,7 \pm 0,30 b \\
(\mathrm{n}=10)\end{array}$ & $\mathrm{C}$ \\
\hline $4^{0}$ & $\begin{array}{c}16,6 \pm 0,21 \mathrm{a} \\
(\mathrm{n}=10)\end{array}$ & A & $\begin{array}{c}47,2 \pm 0,27 \mathrm{a} \\
(\mathrm{n}=10)\end{array}$ & $\mathrm{B}$ & $\begin{array}{c}98,5 \pm 0,19 a \\
(n=10)\end{array}$ & $\mathrm{C}$ \\
\hline
\end{tabular}

${ }^{1}$ Médias seguidas por letras minúsculas nas colunas (C.V.\%=16,12) e maiúsculas nas linhas (C. V.\%=18,21) diferiram entre si pelo teste de Tukey $(\mathrm{P} \leq 0,05)$.

Esta resposta do predador pode ser atribuída às oportunidades de encontro ao acaso, que são maiores no tempo, para maiores
1), é coerente com aqueles obtidos por Hodek (1967), que mostra que, em maiores densidades, o tempo gasto pelo predador

Tabela 2. Número médio ( \pm EP) diário de ninfas de $3 \stackrel{0}{\text { e }} 4^{0}$ ínstares de Schizaphis graminum em diferentes densidades, predadas por larvas e adultos de Scymnus (Pullus) argentinicus.

\begin{tabular}{|c|c|c|c|c|c|}
\hline \multirow{2}{*}{$\begin{array}{l}\text { Predador } \\
\text { (Ínstar/Sexo) } \\
\end{array}$} & \multirow{2}{*}{$\begin{array}{l}\text { Período de avaliação } \\
\text { (dias) }\end{array}$} & \multicolumn{4}{|c|}{ Densidade de afídeos $^{1}$} \\
\hline & & 10 & 25 & & 35 \\
\hline $1 \underline{0}$ & 1,0 & $\begin{array}{c}3,0 \pm 0,15 \text { a } A \\
(n=10)\end{array}$ & $\begin{array}{l}4,6 \pm 0,23 \mathrm{~b} \\
(\mathrm{n}=10)\end{array}$ & $\mathrm{B}$ & $\begin{array}{l}12,3 \pm 0,33 \mathrm{c} \quad \mathrm{C} \\
(\mathrm{n}=10)\end{array}$ \\
\hline $2^{\underline{0}}$ & 1,9 & $\begin{array}{c}3,3 \pm 0,09 \text { a } \quad A \\
(n=10)\end{array}$ & $\begin{array}{l}6,3 \pm 0,18 b \\
(n=10)\end{array}$ & $\mathrm{B}$ & $\begin{array}{l}18,3 \pm 0,12 \text { b C } \\
(n=10)\end{array}$ \\
\hline $3^{\underline{0}}$ & 1,0 & $\begin{array}{c}3,8 \pm 0,13 \text { a } A \\
(n=10)\end{array}$ & $\begin{array}{l}7,6 \pm 0,19 a b \\
(n=10)\end{array}$ & B & $\begin{array}{l}32,7 \pm 0,30 \text { a } C \\
(n=10)\end{array}$ \\
\hline $4^{\underline{0}}$ & 4,7 & $\begin{array}{l}3,5 \pm 0,11 \text { a } A \\
(\mathrm{n}=10)\end{array}$ & $\begin{array}{l}9,9 \pm 0,38 a b \\
(n=10)\end{array}$ & B & $\begin{array}{l}20,7 \pm 0,46 \text { b C } \\
(n=10)\end{array}$ \\
\hline Macho & 64,0 & $\begin{array}{c}5,9 \pm 0,13 \text { a } A \\
(n=10)\end{array}$ & $\begin{array}{c}14,7 \pm 0,30 a b \\
(n=10)\end{array}$ & B & $\begin{array}{l}18,5 \pm 0,56 \text { bc C } \\
(\mathrm{n}=10)\end{array}$ \\
\hline Fêmea & 64,0 & $\begin{array}{c}7,9 \pm 0,21 \text { a } A \\
(\mathrm{n}=10)\end{array}$ & $\begin{array}{c}17,4 \pm 0,18 a \\
(n=10)\end{array}$ & $\mathrm{B}$ & $\begin{array}{l}20,0 \pm 0,28 \text { bc C } \\
(n=10)\end{array}$ \\
\hline
\end{tabular}

${ }^{1}$ Médias seguidas por letras distinta minúsculas nas colunas (C.V.\%=39,84) e maiúsculas nas linhas $($ C. V. $\%=19,13)$ diferiram entre si pelo teste de Tukey $(\mathrm{P} \leq 0,05)$.

densidades da presa, concordando com Solomon (1969). Também, o resultado de um maior número de pulgões capturados e mortos pelo predador em densidades mais altas (Fig. para consumir as presas é menor, com uma maior taxa de consumo, influenciando no número total de presas predadas. Verificou-se, ainda, que houve uma redução 
na predação média diária do 40 ínstar na densidade $35(20,7)$ em relação ao $3^{0}$ ínstar $(32,7)$, (Tabela 2), o que pode ser atribuído a uma diminuição da atividade de predação da larva devido a proximidade da pupação. $\mathrm{O}$ aumento da predação ocorrido na densidade 10 até o $3^{0}$ ínstar e posterior diminuição no $4^{0}$ ínstar não foram significativos, mostrando que há uma semelhança nos quatro ínstares nesta densidade diferindo das densidades de 25 e 35 pulgões, onde houve uma predação mais heterogênea.

Houve, também, influência da densidade na capacidade de predação diária de adultos de $S$. argentinicus (Tabela 2). Ocorreu um aumento na predação, quando a densidade de presas disponíveis aos adultos machos e fêmeas aumentou. Foi observado que as fêmeas apresentaram uma maior capacidade de predação que os machos $(7,9 ; 17,4$ e 20,0 para fêmeas e 5,9; 14,7 e 18,5 para machos respectivamente), com uma tendência para a significância entre os sexos e entre as densidades (Tabela 2). Esses resultados são próximos dos obtidos por Saucedo-Gonzales \& Reyes-Villanueva (1987), que verificaram uma média diária de consumo de Orius insidiosus (Say) sobre Caliothrips phaseoli (Hood) de 12,2 e 19,2 tripes, para machos e fêmeas respectivamente. Constatou-se que houve um aumento da predação com o aumento da densidade da presa de 10 para 25, sendo mais evidente nas fêmeas do que nos machos. Entretanto, quando a densidade passou de 25 para 35 presas, o número de ninfas predadas foi muito próximo (Tabela 2). Pode-se inferir, nessas condições, que é em torno da densidade 25 a coincidente com as necessidades nutricionais do macho (em média 14,7 ninfas/dia); contudo, o mesmo não acontece com as fêmeas, que requerem um maior consumo de presas devido certamente a atividade de oviposição. Esse fato foi observado por Wiedenmann \& O'Neil (1990) em $P$. maculiventris, que sobrevive e se reproduz em baixas quantidades de presas, mas as fêmeas reduzem a reprodução até aumentar a quantidade disponível de presas.

Em relação ao tempo de busca e de manuseio das ninfas de $S$. graminum pelas larvas de S. argentinicus (Tabela 3), constatou-se que foram menores no $4^{0}$ ínstar em todas as densidades, sendo esses resultados semelhantes aos obtidos por E.D.

Tabela 3. Tempo (minuto) $(\mathrm{X} \pm \mathrm{EP})$ de busca (TB) e de manuseio (TM) de ninfas de $3^{\stackrel{0}{ } \mathrm{e}}$ $4^{0}$ ínstares de Schizaphis graminum em diferentes densidades, por larvas e adultos de Scymnus (Pullus) argentinicus.

\begin{tabular}{lcccccc} 
Predador & \multicolumn{7}{c}{ Densidade de afídeos ${ }^{1}$} \\
(Ínstares)
\end{tabular}

${ }^{1}$ Médias seguidas por letras nas colunas diferirem entre si pelo teste de Tukey $(\mathrm{P} \leq 0,05)$. C.V. $\%=12,17$ para fase larval e C.V.=25,43 para adultos de S. argentinicus. 


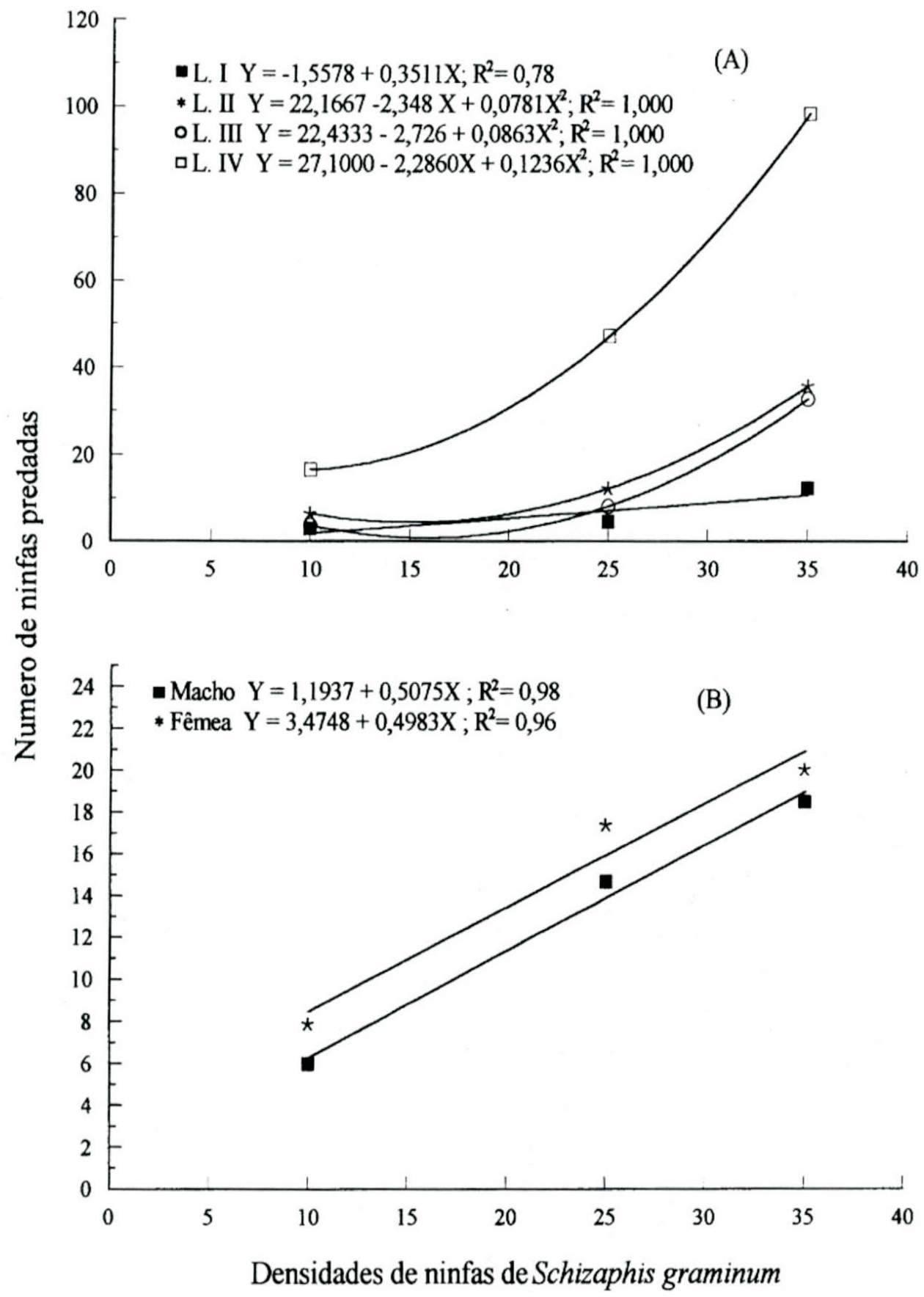

Figura 1. Resposta funcional de larvas (L I a L IV) (A) e adultos (B) de Scymnus (Pullus) argentinicus em diferentes densidades de ninfas de $3^{0}$ e $4^{0}$ ínstares de Schizaphis graminum. 
Saini et al. (não publicado), onde a taxa de busca de $P$. connexivus aumentou com a idade desse predador e o tempo de manuseio decresceu com a idade. Quando as densidades foram de 25 e 35 ninfas, não houve diferenças significativas entre o tempo de busca dos diferentes ínstares. Assim, pode-se imaginar que em maiores densidades de presas os encontros ao acaso são maiores, afetando o ato de busca do predador. Estas observações concordam com Tostowaryk (1972), em estudo com P. modestus. O tempo médio de busca despendido em cada ínstar na densidade de 10 ninfas (19'; 10'; 12'e 04' do $1^{0}$ ao 4ํㅜㄴ ínstar) foi maior do que nas demais densidades devido às menores chances de encontro ao acaso, concordando com os resultados de Wiedenmann \& O'Neil (1991), em que o predador $P$. maculiventris apresentou busca pela presa em uma área maior e mais longe em baixa densidade de presas do que em alta densidade. Para S. (Pullus) argentinicus, o ato de busca foi maior nas fêmeas (03') do que em relação aos machos (09'), nas três densidades estudadas enquanto que o tempo de manuseio foi igual para ambos os sexos (Tabela 3).

Observou-se que o $2^{0}, 3^{0}$ e $4^{0}$ ínstares (Fig. 1A) e todo o ciclo biológico (Fig. 1B), evidenciaram uma resposta funcional Tipo II, em forma de ascensão linear, aproximandose dos resultados propostos por Holling (1959) e Trexler et al. (1988). Esta tendência foi mais importante no $2^{0}, 3^{0}$ e $4^{0}$ ínstares, devido ao aumento da predação ao passar da densidade 25 para 35 ninfas (Fig. 1A). No $1^{\underline{0}}$ ínstar (Fig. 1A), machos e fêmeas (Fig. 1B) apresentam uma ascenção linear sem tendência a formar uma curva. Esses resultados concordam em parte com os obtidos por Garcia et al. (1975), onde larvas

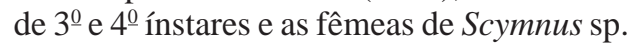
mostram uma resposta funcional em forma de ascensão linear. São também coerentes com aqueles obtidos por Ofuya \& Akingbohungbe (1988), onde o predador Cheilomenes lunata (Fabr.), alimentando-se de presa Aphis craccivora (Koch), apresentou uma resposta funcional Tipo II. No caso de $S$. argentinicus este tipo de resposta foi determinada em função do $2^{\underline{0}}, 3^{0}$ e $4^{0} \underline{\text { ínstares. }}$

A resposta funcional Tipo II verificada para $S$. argentinicus se ajusta aos modelos observados com outros predadores, (p.ex., Saucedo-Gonzales \& Reyes-Villanueva 1987).O tipo de resposta funcional apresentada é fundamental e pode determinar a eficiência de $S$. argentinicus no controle da presa e indicar o número de predadores necessários para a liberação em programas de controle biológico.

\section{Literatura Citada}

Arioli, M.C.S. \& D. Link. 1987. Coccinelídeos de Santa Maria e arredores. Rev. Cent. Ciên. Rurais 17:1.

Bartoszeck, A.B. 1975. Afídeos da macieira (Pyrus malus L.), seus predadores e parasitas. Acta Biol. Paranaense 4: 3374.

Bartoszeck, A.B. 1976. Afídeos da ameixeira (Prunus domestica L.) e pessegueiro (Prunus persica Sto.), seus predadores e parasitas. Acta Biol. Paranaense 18:5358.

Garcia, U.B., M.T. Zapata \& A.N. Bel. 1975. Respuesta funcional y numérica de Scymnus sp.a diferentes densidades de Aphis gossypii Glover. Rev. Per. Entomol. 18:53-58

Gassen, D. N. \& F.J. Tambasco. 1983. Controle biológico de pulgões do trigo no Brasil. Inf. Agropec. 9: 49-51.

Gravena, S. 1979. Dinâmica populacional do pulgão verde Schizaphis graminum (Rondani, 1852) (Homoptera:Aphididae) e inimigos naturais associados ao sorgo granífero em Jaboticabal, SP. An. Soc. Entomol. Brasil 8:325-334

Hagen, K.S. \& R. van den Bosch. 1968. Impact of pathogens, parasitoids, and 
predators on aphids. Annu. Rev. Entomol. 13:325-384.

Hodek, I. 1967. Bionomics and ecology of predaceous Coccinellidae. Annu. Rev. Entomol. 12:79-104.

Holling, C.S.1959. Some characteristics of simple types of predation and parasitism. Can. Entomol. 91:385-398.

Ofuya, T.I. \& A.E. Akingbohungbe. 1988. Functional and numerical responses of Cheilomenes lunata (Fabricius) (Coleoptera:Coccinellidae) feeding on the cowpea aphid, Aphis craccivora Koch (Homoptera: Aphididae). Insect Sci. Applic. 9:543-546.

Saucedo-Gonzales, J. \& F. ReyesVillanueva. 1987. Resposta funcional de Orius insidiosus (Hemiptera: Anthocoridae) sobre Caliothrips phaseoli (Thysanoptera:Thripidae). Folia Entomol. Mex. 71:27-35.

Solomon, M.E. 1969. Population dynamics. Londres: Edward Arnold, Study, 18, 59p.
Tostowaryk, W. 1972. The effect of prey defense on the functional response of Podisus modestus (Hemiptera: Pentato midae) to densities of the sawflies Neodiprion swainei and N. pratti banksianae (Hymenoptera: Neodiprionidae). Can. Entomol. 104:61-69.

Trexler, J.C., C.E. McCulloch \& J.Travis. 1988. How can the functional reponse best be determined? Oecologia 76:206214.

Wiedenmann, R.N. \& R.J. O'Neil. 1990. Effects of low rates of predation on selected life history characteristics of Podisus maculiventris (Heteroptera: Pentatomidae). Can. Entomol. 122: 271 283.

Wiedenmann, R.N. \& R. J. O'Neil. 1991. Searching behavior and time budgets of the predator Podisus maculiventris. Entomol. Exp. Appl. 60:83-93.

Recebido em 31/01/96. Aceito em 06/10/97. 